\title{
Control of Water and Gas Coning by Dynamic Pressure Barrièr: Application to a Carbonate Reservoir
}

* De Ghetto G.; ** Kossack Ch.

* Agip S. p. A., Italy

** Consultant, Germany

\begin{abstract}
Copyright 1995, Steering Committee of the European IOR - Symposium.
This paper was presented at the 8th. European IOR - Symposium in Vienna, Austria, May 15 - 17. 1995

This paper was selected for presentation by the Steering Committee, following review of information contained in an abstract submitted by the author(s). The paper, as presented has not been reviewed by the Steering Committee.
\end{abstract}

1

\section{ABSTRACT}

The ability of a fluid continuously injected at near the water-oil contact or gas-oil contact (while producing oil) to reduce the coning was investigated by numerical reservoir simulation.

The injection creates a dynamic barrier to the flow of water or gas into the well.

The study was made on an actual carbonate reservoir that has an aerial variation of fracture density. In regions of low fracture density, gas from the cap cones into the wells and, in areas of high fracture density, water from the aquifer cones into the wells. In both areas the dominate mechanism of fluid transport is through the fractures.

The simulations were applied to actual well/areal models that had been history matched to the actual pressure/production/coning history of the wells. Since this study was applied to a real field with the goal of possibility field testing the process, it was of particular interest to determine the rates of injection of fluid ( polymer or foam) that would be required to alleviate the coning. Sensitivity studies were made to see the effect on water/gas coning of: polymer/foam injection rates, polymer/foam injection location and timing, polymer/foam viscosity, and oil production rate. This paper will give the key results of the study.

It was found from the simulations that the injection of the viscous polymer solution above the water-oil contact did not delay the breakthrough of water into the well. But, the after breakthrough rise in water cut was substantially reduced by the high rate,
$0.00092 \mathrm{~m}^{3} / \mathrm{s}$, injection of a high viscosity ( 20 times the viscosity of reservoir brine) polymer solution: $4.4 \mathrm{mPa} \mathrm{s}$. The results show that the polymer process can increase the cumulative oil recovery by a factor of two compared with a standard production well.

In the gas coning case the injection of sufficient quantities of polymer or foam would delay the breakthrough of gas for several years.

The paper presents also the selection of the fluid to be used in field for creation of an effective dynamic barrier and the optimum completion to accomplish this task.

\section{INTRODUCTION}

\subsection{Background}

The coning of gas or water into oil wells will often lead to reduced oil rates and a lower recovery factor for the reservoir.

If the GOR or water-cut are unacceptably high the current remedy, often temporarely effective, is: a) to reduce the production rate, $b$ ) to re-complete the producing interval by the use of cement or sand plug and reperforating, c) to re-enter the well for drilling horizontal section.

Solutions b) and c) are also very expensive.

When natural horizontal barriers exist in a reservoir they often effect the breakthrough and coning of gas or water into the well. Reservoir engineers have always wanted to create man-made 
horizontal barriers in situations where natural barriers do not exists. This study looked at the placement of such barriers and their effect on the coning of gas and water.

Many other methods ( in addition to those above mentioned ) for suppressing or, at least, alleviating gas and water coning have been proposed in literature; in this respect an excellent review has been recently made by Rayan and Luhing ${ }^{1}$.

All the methods basically involve either creation of barriers to water up flow or modification of the mobility ratio.

Smith and Pirson ${ }^{2}$ were the first to make an experimental investigation to develop a method to control water coning by injecting oil at a point below the producing interval; under their test conditions they found little benefit from the use of impermeable barriers.

Karp et al ${ }^{3}$ considered several factors involved in creating, designing and locating horizontal barriers for controlling water coning. After lab tests they concluded that, among other things, reservoirs containing high viscosity oils or having low permeabilities or small oil thickness are poor candidates for the barrier treatment.

Pollock and Shelton ${ }^{4}$ have presented a method to reduce water coning by gas injection. Their method reduces water flow and increase oil production. Their strategy involves injection of a gas having higher solubility in oil than in water. Under these conditions, a higher gas saturation is created at the water oil contact thereby decreasing the relative permeability of the formation to water with resulting decrease in the water production rates. Hoyt ${ }^{5}$ has suggested a method to delay water coning by imposing of a flow barrier by recirculating an extraneous fluid, such as produced fluid hydrocarbons, injected into the formation via well perforations below the production perforations in the wellbore. The recirculation of the produced fluid provides a gradient barrier to delay coning. Luhning and Rronaghan ${ }^{6}$ have proposed a technique for water coning reduction that involves the injection of non-condensing gas in a nearby injection well while the production well is simultaneously produced. The injected gas establishes communication with the production well along the oil-water interface forming a layer having high gas saturation; this gas "blanket" suppresses the water production.

Others have suggested methods to alleviate water coning that imply injection of gas.

To estimate the benefit of horizontal barriers for coning control, Ekrann ${ }^{7}$ has recently presented an analytical approach.

Water or gas coning can be reduced by the proper positioning of a dynamic barrier made by the continuous injection of a fluid at near water oil / gas oil contact. This dynamic barrier reduces coning by the combination of two mechanisms: (1) a low mobility fluid blocks the flow of water/gas in to the oil zone and (2) the injection of the viscous fluid creates a high pressure zone at the well which keeps the lower pressure water/gas away from the well. The ability of such a barrier to delay the water/gas breakthrough and reduce the rate of rise of the water-cut / GOR after the breakthrough depends on the particular situation. Viscosity of the injected fluid, strength of the aquifer, mobility ratio, vertical and horizontal permeability, presence of fractures, etc. will all effect the ability of the barrier coning. The disadvantage of the fluid barriers is that the fluid can be pulled into the well and be produced which reduces the size of the barrier.

\subsection{Current Application}

An off-shore fractured carbonate field was chosen to test the application of these dynamic barriers. The field has both a large gas cap and an active aquifer. In this field more than $\mathbf{5 0}$ wells have been drilled and are producing. At the high oil production rates required by the economics, some of the wells have severe gas or water coning. The expense of converting these wells into horizontal wells is very high. Thus, a cheaper technique was needed to reduce the coning with the existing vertical wells.

The fracture density in this field varies from region to region. The matrix permeability is important, but the fractures dominate the fluid flow in all locations. In regions where the fracture density is low, especially under the gas cap, the gas coning or fingering through the fractures develops very rapidly. In regions where the fracture density is high the aquifer water is conned into the wells after a period of time.

The simulation of the dynamic barriers was applied to well or area models that had been history matched (oil rates, pressures, GORs and water cuts) to the actual field results.

This study was an applied one with the goal of determining if the process would dynamically work. It was of economical interest to see the quantities of chemical required and the injection and productions rates of oil and chemical. Thus, a sensitivity study was made to several key parameters, such as:

- polymer/ foam viscosity

- polymer/foam injection rate

- oil production rate

- polymer/foam injection location

- injection/production timing

\section{NUMERICAL DETAILS}

\subsection{Description and Grid - Gas Coning Case}

For the gas coning study a standard black oil model (ECLIPSE, single porosity) was used. The effect of the fracture permeability was modeled by 
increasing the rock permeability. Special representations needed to be made to model a polyinier/foam with a density different than the water phase. The details are available in a full report from the authors. Space does not permit the inclusion of all the numerical and geological description so only the key details are included.

The gas coning well will be called "well 1 " during the remainder of the discussion. A radial model consisted of a 20 by 1 by 18 (nr-ntheta-nz) radial grid was used. The gas-oil contact was positioned so that layers 1 and 2 represented the gas cap and the top of layer 3 represented the top of the oil column. A relatively fine grid was defined between the gas-oil contact and the well's completion interval so that the location and movement of the polymer or foam would be more accurately simulated.

\subsection{Description and Grid - Water Coning Case}

For the water coning study a dual porosity, single permeability, black oil model with the ECLIPSE polymer option was used. It was necessary to use the dual porosity model because, in the areas where the water coning is the dominate problem, the fracture density is very high and a dual porosity description is required to successfully history match the wells performance.

The water coning well will be called "well 2" during the remainder of the discussion. A Cartesian sector model with the well located near the center of the grid was used for these simulations. The grid was 7 by 5 by 34 blocks (nx-ny-nz). The horizontal fracture permeability was in the range of 1.97E-6 to $5.91 \mathrm{E}-6 \mathrm{~m}^{2}$, the vertical fracture permeability was $1.97 \mathrm{E}-5 \mathrm{~m}^{2}$, the matrix stack height was $3.28 \mathrm{~m}$, the matrix-fracture transfer function was $0.067 \mathrm{~m}^{-2}$, and the effective fracture porosity was 0.018 .

\section{BASE CASES WITH NO CHEMICAL INJECTION}

\subsection{Base Case - Gas Coning}

The base case for the barrier coning study involved completing the vertical oil produced as one would do in a standard situation. The production well was run at a constant oil production rate of 0.0037 st $\mathrm{m}^{3} / \mathrm{s}$ for two years after its start-up ( start-up in all cases is at day 60). When the oil well was run in the absence of any barrier, the resulting GOR is presented in Figure 1. This defined the base GOC case for the study. The gas coned down into the well in just a few days. The GOR then climbed quickly to about $950 \mathrm{st} \mathrm{m}^{3} / \mathrm{m}^{3}$. All coning barrier situations should be then compared to this base case.

\subsection{Base Case - Water Coning}

The oil production completion interval for well -2 was completed in the fracture layers $39.6 \mathrm{~m}$ above the water-oil contact. The results with no polymer injection showed a water break through in 363 days and the well was shut in after 623 days.

A plot of the water cut versus time is given in Figure 2.

The plot has a 2.7 year scale so the water cuts can later be directly compared with the polymer injection cases, Section 5.6.

5

\section{EFFECTS ON CONING BY DYNAMIC PRESSURE BARRIERS}

\subsection{On gas coning - The polymer injection situation}

The densities, at reservoir conditions, of the gas ( $\left.272 \mathrm{~kg} / \mathrm{m}^{3}\right)$, the oil $\left(641 \mathrm{~kg} / \mathrm{m}^{3}\right)$ and the brine/water $\left(977 \mathrm{~kg} / \mathrm{m}^{3}\right)$ define the limits for the injection of fluids to create a barrier. In general, a polymer solution is a mixture of polymer and water. But such a mixture at these reservoir conditions would result in a mixture with a density higher than $961 \mathrm{~kg} / \mathrm{m}^{3}$. This mixture, when injected at the gas-oil contact, would drift down toward the water-oil contact and most likely be produced by the oil well. Thus, for this polymer injection process, it was assumed that a polymer solution could be made where the reservoir condition density would be near that of the oil so the gravity effect would be minimized. In particular, for the well 1 simulation, the reservoir condition density of the polymer solution was chosen to be $721 \mathrm{~kg} / \mathrm{m}^{3}$. This solution when injected would slowly drift down towards the water-oil contact. Since 0.00018 to $0.00092 \mathrm{~m}^{3} / \mathrm{s}$ would be injected, the assumption is that a reasonable size barrier would still be formed and would be effective against gas coning.

\subsection{Results}

The key results of simulation the polymer injection situation are summarized in Table 1.

These results are for the polymer injection just above the gas-oil-contact. When the polymer is injected just below the gas-oil-contact the results were nearly identical to the above results and are not shown.

The positive effect on gas coning vs time for an injection rate of $0.00018 \mathrm{~m} 3 / \mathrm{s}$ and viscosity of 10 $\mathrm{mPa} \mathrm{s}$ is depicted in Figure 3. The graph shows also the production rate of the polymer.

The production of the low mobility polymer is important since if all or most of the injected polymer is produced it can not create an effective barrier. Note that the presence of polymer between the GOC and the perforations can be an effective relative permeability block even if most of 
the injected polymer or foam is being produced, but these are expensive fluids to use as a relative permeability block alone.

\subsection{Analysis of the Results}

An analysis of the results tell us the following about the polymer injection system:

- The best case is the $10 \mathrm{mPa}$ s polymer that is injected just above the GOC at a rate of $0.00092 \mathrm{~m}^{3} / \mathrm{s}$. In this case the coned gas is always zero and the maximum polymer production rate, with $0.0037 \mathrm{st} \mathrm{m} / \mathrm{s}$, is $0.0004 \mathrm{~m}^{3} / \mathrm{s}$.

- The $1 \mathrm{mPa}$ s polymer, in general, flows too easily in to the production well and a large barrier is not formed.

- The polymer injection rate is a critical parameter for the success of the operation of the production well. At an oil production rate of 0.0037 st $\mathrm{m}^{3} / \mathrm{s}$ a polymer injection rate of $0.00018 \mathrm{~m}^{3} / \mathrm{s}$ is insufficient for both the high and low viscosity polymers. An injection rate of $0.00092 \mathrm{~m}^{3} / \mathrm{s}$ is very effective for the $10 \mathrm{mPa} s$ polymer. One could optimize, at the well site, the polymer injection rate as a function of the oil production rate so the well would be gas free.

\subsection{On gas coning - The foam injection situation}

The densities, at reservoir conditions, of the gas $\left(273 \mathrm{~kg} / \mathrm{m}^{3}\right)$, the oil $\left(641 \mathrm{~kg} / \mathrm{m}^{3}\right)$ and the brine/water $\left(977 \mathrm{~kg} / \mathrm{m}^{3}\right.$ ) define the limits for the injection of fluids to create a barrier. In general, a foam solution is a mixture of surfactant, water and gas (usually produced gas). Since the foam is mostly gas, at reservoir conditions the foam mixture will have a density slightly larger than 273 $\mathrm{kg} / \mathrm{m}^{3}$. For the scoping study of foam injection into well 1 , the density was chosen to be $400 \mathrm{~kg} / \mathrm{m}^{3}$. This number can be easily changed if desired, but small variations in the value will have very small effects on the overall results.

The results, for the foam injection, are nearly identical to the polymer results. The GOR and foam production rates are so similar to the polymer results no plots are necessary. The only slight difference is that the foam production rate is lower than the polymer production rate at the same point in time. This is because of the density difference between the two mixtures.

\subsection{Sensitivity to Oil Production Rate and Optimal Foam Injection Rate}

When the oil production rate was increased to 0.0055 and 0.0074 st $\mathrm{m}^{3} / \mathrm{s}$, with injection of $0.00092 \mathrm{~m}^{3} / \mathrm{s}$ of $10 \mathrm{mPa}$ s foam, no break through was seen at $0.0055 \mathrm{st} \mathrm{m}^{3} / \mathrm{s}$ and a limited GOR of $320 \mathrm{st} \mathrm{m}^{3} / \mathrm{m}^{3}$ was seen at $0.0074 \mathrm{st} \mathrm{m}^{3} / \mathrm{s}$.
An approximate optimum foam ( $10 \mathrm{mPa} \mathrm{s}$ ) injection rate was found for the oil production rate of $0.0037 \mathrm{st} \mathrm{m}^{3} / \mathrm{s}$ by simulating several cases. As the $10 \mathrm{mPa}$ s foam injection rate is increased from 0.00018 to $0.00092 \mathrm{~m}^{3} / \mathrm{s}$ the gas breakthrough time increased from 82 days ( at $0.00037 \mathrm{~m}^{3} / \mathrm{s}$ ) to no breakthrough at $0.00064 \mathrm{m3} / \mathrm{s}$. Thus, one could say that of this reservoir/well situation the critical foam rate is between 0.00055 and $0.00064 \mathrm{~m}^{3} / \mathrm{s}$

\subsection{On water coning - The polymer injection situation}

In the injection cases, the polymer injection occurred $7.6 \mathrm{~m}$ above the water oil contact. This would allow the polymer to spread out somewhat before it contacted the in-place brine. For this study the fixed oil rates $0.0018,0.0037$ and 0.0055 st $\mathrm{m}^{3} / \mathrm{s}$ made the comparisons of cases easier. The simulations were run until the water cut reached 0.6, as per current field experience. The polymer injection rate was $0.00092 \mathrm{~m}^{3} / \mathrm{s}$ and its viscosity was 10 times the viscosity of in place brine.

The injection and production both began at the start of the simulation. The standard oil rate for the following results was $0.0037 \mathrm{st} \mathrm{m}^{3} / \mathrm{s}$.

The results were a breakthrough of water at 379 days compared with 363 days with no polymer injection. These numbers are effectively the same since the breakthrough point was loosely estimated at the point when the water cut reached 0.01 . This approach was used since numerical dispersion tended to smear out the breakthrough front. As we will later see for all the cases, the injection of polymer did not effect the water breakthrough point. It was concluded that the active expansion of aquifer towards the producing well was not effected by the layer of polymer at the water-oil contact.

The well in the base polymer case run was shut-in at 973 days ( 2.7 years ).

A view of the water cut versus time for this case is provided in Figure 4. The water cut results should be compared with Figure 2. The effect of the injection of $0.00092 \mathrm{~m} / \mathrm{s}$ of 10 times viscosity polymer was a decrease in the rate of rise in the water production (water cut). This was a result of the fact that the well produced water which was a mixture of reservoir brine and injected polymer solution. This mixture had an increased viscosity ( somewhere in between $0.22 \mathrm{mPa} s$ of the reservoir brine and $2.2 \mathrm{mPa} s$ of the reservoir condition polymer as injected), thus the mobility of the produced water was reduced. This resulted in a reduced water cut.

\subsection{Sensitivity Results}

Sensitivity simulations were made to the polymer viscosity, oil production rate and polymer injection rate. Because of space limitations only a few key results are summarized below. 
The beneficial effect of polymer injection can be seen in Figure 5 where the cumulative oil produced increases with polymer injection rate and viscosity.

Results from sensitivity studies on the incremental oil recovery are as follows:

1. Increasing the polymer viscosity from 10 to 20 times the brine viscosity had times

a) only a limited additional effect on the shut-in

b) a strong effect on cumulative oil produced ( $27 \%$ increase at the higher viscosity )

2. A reduction of the polymer injection rate to $0.00046 \mathrm{~m}^{3} / \mathrm{s}$ ( from $0.00092 \mathrm{~m}^{3} / \mathrm{s}$ ) reduced the incremental (compared to no polymer injection ) cumulative oil produced at shut-in by $43 \%$. A further reduction of the polymer injection rate to $0.00018 \mathrm{~m} 3 / \mathrm{s}$ reduced the incremental cumulative oil produced at shut-in by $74 \%$. The reduction of the polymer injection rate has a significant effect on the coning.

3. A reduction in the oil production rate to 0.0018 st $\mathrm{m}^{3} / \mathrm{s}$ resulted in an increase in the incremental cumulative oil produced of $67 \%$, while an increase in the oil production rate to $0.0055 \mathrm{st} \mathrm{m}^{3} / \mathrm{s}$ resulted in an decrease in the incremental cumulative oil produced of $38 \%$. The economical analysis of the particular case would determine the optimum oil rate.

OPTIMUM COMPLETION FOR CONING CONTROL BY DYNAMIC BARRIER

At present the producing wells of the field are completed with a $31 / 2$ " (internal diameter $76 \mathrm{~mm}$ ) string that is not suitable as such for realizing coning control by dynamic barrier that, as described above, requires simultaneous injection and production. To accomplish this task well recompletion by pulling the present string and new perforations close to GOC for gas coning and close to WOC for water coning control are necessary.

The recommended completion scheme for coning control is depicted in Figure 6.

For gas coning control, oil is produced through the long string and the fluid, that entering into the reservoir creates the dynamic barrier, is injected into the short one.

Viceversa for water coning control.

Both strings are equipped with tubing retrievable safety valve surface controlled by control lines. It has to be noted that both long and short strings are not mechanical linked to the packers so they can freely move up and down for compensating the tubing tension caused by the injection of the cold fluid.
In the simulation above, both polymer and fôn have been discussed as fluids to be injected for the creation of dynamic pressure barriers. It has been demonstrated, however, that the foam, despite its lower density with respect to polymer, does not have significant benefit in coning control if compared to polymer.

In addition, only polymers have been considered because of the following : a) the foam preparation at the well site, because of the gas handling, presents difficulties, b) foam has higher well head injection pressure due to lighter hydrostatic column in the injection string, c) foam preparation and injection presents higher costs than polymer.

For the application in low temperature reservoir there are not big problems and all the necessary information about polymer characteristics and field response are available in literature.

Problems arise, however, in case of high temperature, say above $100 \mathrm{deg} C$. The application in the reservoir studied here, with a temperature of $125 \mathrm{deg} C$, thus, could present some critical aspects.

As above discussed the viscosity of the injected fluid for effectively acting against cone growing should be $5-10 \mathrm{mPa} s$ at RC for gas control and around $3 \mathrm{mPa} s$ at $\mathrm{RC}$ for water control. Among the polymers available and used in the oil industry, only two present the characteristics for application under such harsh condition, namely xanthan and scleroglucan. The laboratory test data of these polymers are quite numerous in the literature ${ }^{8}$, they are however quite scarce at temperature above $100 \mathrm{deg} \mathrm{C}$.

Recently an excellent paper has been published in this respect ${ }^{9}$ putting insight in this issue. This work demonstrates that even at 120-130 deg $C$ these polymers exhibit acceptable stability and viscosity, for the required job. At these temperatures, for both polymers, many tests were conducted and relevant data of viscosity vs polymer concentration, shear rate, and water salinity are reported in the paper.

All such data are encouraging and demonstrate the suitability of xanthan and scleroglucan for application under harsh condition and, ultimately, in the carbonate reservoir of the case under examination.

To determine the surface concentration of the polymer in sea water ( the field is offshore) having the necessary level of down hole viscosity, first of all, the shear rate of the polymer, while entering in formation, has to be calculated.

In our case, for the optimum injection rate, as previously simulated, $0.00055-0.00092 \mathrm{~m}^{3} / \mathrm{s}$, the calculated range obf shear rate is $10-100 \mathrm{~s}-1$. For such values of shear rate, the surface 
concentration of polymer, having a reservoir viscosity in the range $3-10 \mathrm{mPa} s$, has to be about $1 \%$.

The relevant cost estimated for the polymer is about $5,000 \$ /$ day for an average well. Other operation costs linked to injection are quite negligible because: a) sea water can be used, b) the injection pressure is very low, it is estimated at $700-100 \mathrm{kPa}, \mathrm{c}$ ) less than $1 \mathrm{kw}$ pump is required for injection .

5000 \$/day has not to be considered an high cost because largely compensated by the increase in oil recovery obtainable by the coning control method, as demonstrated above. At an oil price of $15 \$ / \mathrm{bbl}$, a oil rate of only $0.00055 \mathrm{st} \mathrm{m} / \mathrm{s}$ of oil are sufficient to cover the OPEX cost of the operation.

It is however clear that these are only indications for the field testing; the optimum injection rates and polymer viscosities, that maximizes the revenue must be found at the well.

It is our opinion that, in field, such operation doesn't present any difficulty.

\section{CONCLUSIONS}

Both the foam and the polymer were shown to create an effective dynamic barrier at the gas-oil contact if the injected fluid viscosity was in the range of $3 \cdot 10 \mathrm{mPa}$ at $\mathrm{RC}$ and if sufficient quantities of fluid were continuously injected.

In this study, when the oil rate was $0.0037 \mathrm{st} \mathrm{m}^{3} / \mathrm{s}$ ( 2000 stb/day ), a polymer (or foam ) injection rate of between 0.00055 and $0.00092 \mathrm{~m} / \mathrm{s}$ ( 300 and $500 \mathrm{r} /$ day ), with a viscosity of about $10 \mathrm{mPa} \mathrm{s}$ at $\mathrm{RC}$, was required to completely eliminate the gas coning.

The tecnique worked for both cases of injection: above or below the gas-oil contact.

The less dense foam performed slightly better if every thing else was equal.

The simulations showed that the polymer had very little effect on the waters breakthrough time. However, when an injection rate of $0.00092 \mathrm{~m} / \mathrm{s}$ ( 500 BPD) was used with a viscosity solution of $2.2 \mathrm{mPa} \mathrm{s}$, the resulting dynamic polymer barrier could reduce the rate of the increase in the water cut so that the life of the well would be increased by 3 years, with an additional oil recovery of $56 \%$.

\section{AKNOWLEDGMENT}

We thank Agip SpA for permission to publish this paper.

\section{REFERENCES}

1. RAJAN, S.V., LUHNING, R. W., Water Coning Suppression, The Journal of Canadian Petroleum Technology, April 1993, Vol. 32, No.4

2. SMITH, C.R., PIRSON, S.J., Water Coning Control in Oil Wells by Fluid Injection; Soc. Pet. Eng. Journal, Vol 3, No. 4, 1963.

3. KARP, J.C., LOWE, D.K., Horizontal Barriers for Controlling Water Coning; Journal of Petroleum Technology, July 1962

4. POLLOK, C.B.,SHELTON, J.L., Method for Decreasing Water Production by Gas Injection in a Single Well Operation.; Canadian Patent No. 866, 573, March 23, 1971.

5. HOYT, D.L., Gradient Barrier in a Secondary Recovery Operation to Inhibit Water Coning; U.S. Patent No. 3, 825, 070, July 23,1974

6. LUHNING, R.W., RONAGHAN, K.R., Method for Controlling Water Coning in Oil Wells; Canadian Patent No. 1, 239, 088, July 12, 1988.

7. EKRANN, S., On the Protection Against Coning Provided by Horizontal Barriers of Limited Lateral Extent; 6th European IOR-Symposium in Stavanger, Norway, May 21-23,. 1991

8. SORBIE, K. S., Polymer Improved Oil Recovery, Blakie and Son Ltd, 1991.

9. AUDIBERT, A., NOIK, C., LECOURTIER, J., Behavior of Polysaccharide Under Harsh Conditions; The Journal of Canadian Petroleum Technology, September 1993, Vol. 32, No. 7 
i) Table 1. Results of polymer injection at the gas-oil contact

\begin{tabular}{|c|c|c|c|c|}
\hline $\begin{array}{c}\text { Polymer Injection } \\
\text { Rate, }\end{array}$ & $\begin{array}{c}\text { Polymer } \\
\text { Viscosity* } \\
\text { (mPa s) } \\
\text { * at surface } \\
\text { conditions }\end{array}$ & $\begin{array}{c}\text { Effect on Gas } \\
\text { breakth. (BT) } \\
\text { compared to no } \\
\text { injection case }\end{array}$ & $\begin{array}{c}\text { Maximum GOR } \\
\text { (minus solution } \\
\text { gas ) during } \\
\text { simulation, } \\
\text { st m3/m3 E+3 }\end{array}$ & $\begin{array}{c}\text { Maximum } \\
\text { Polymer } \\
\text { Production Rate, } \\
\mathrm{m3} / \mathrm{s} \mathrm{E-4}\end{array}$ \\
\hline 1.84 & 1 & no effect & 3 & 1.84 \\
\hline 1.84 & 10 & no effect & 1 & 1.1 \\
\hline 9.2 & 1 & delayed 180 days & 1 & 9.2 \\
\hline 9.2 & 10 & No gas BT & 0 & 4.05 \\
\hline
\end{tabular}

Fig. 1 - Gas oil ratio vs time for the base case: no polymer injection

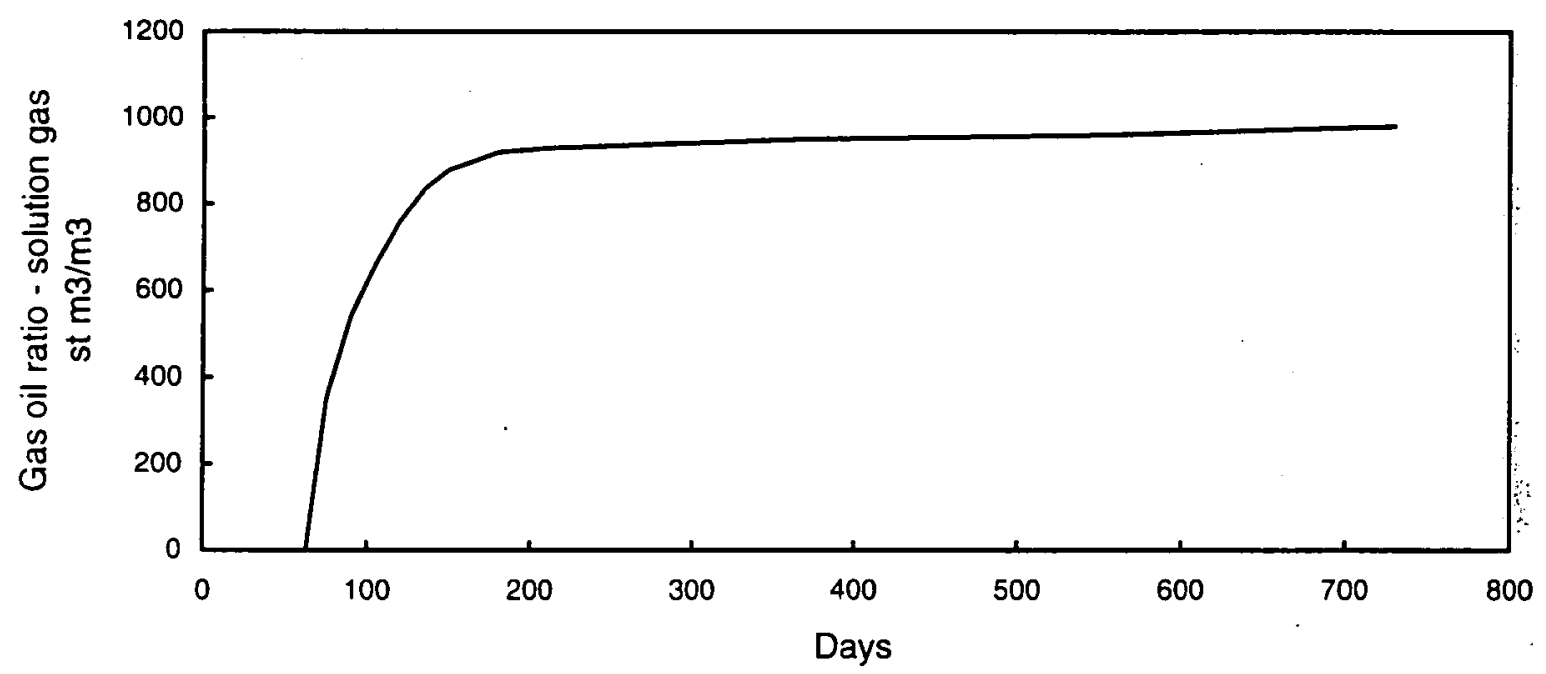

Fig. 2 - Water cut vs time for the base case No polymer injection

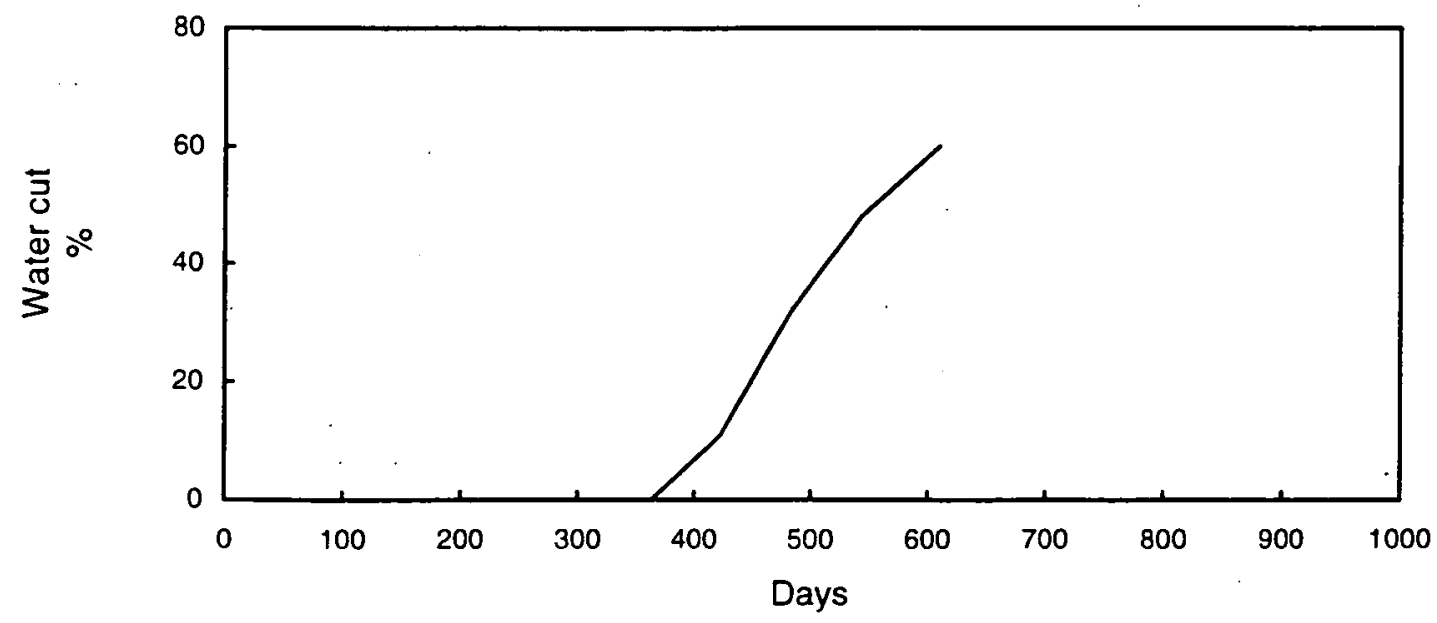


Fig. 3 - Effect of polymer injection on gas coning. Polymer injection rate $=0.00018 \mathrm{~m} 3 / \mathrm{s}$, polymer viscosity $=10 \mathrm{Mpa} \mathrm{s}$
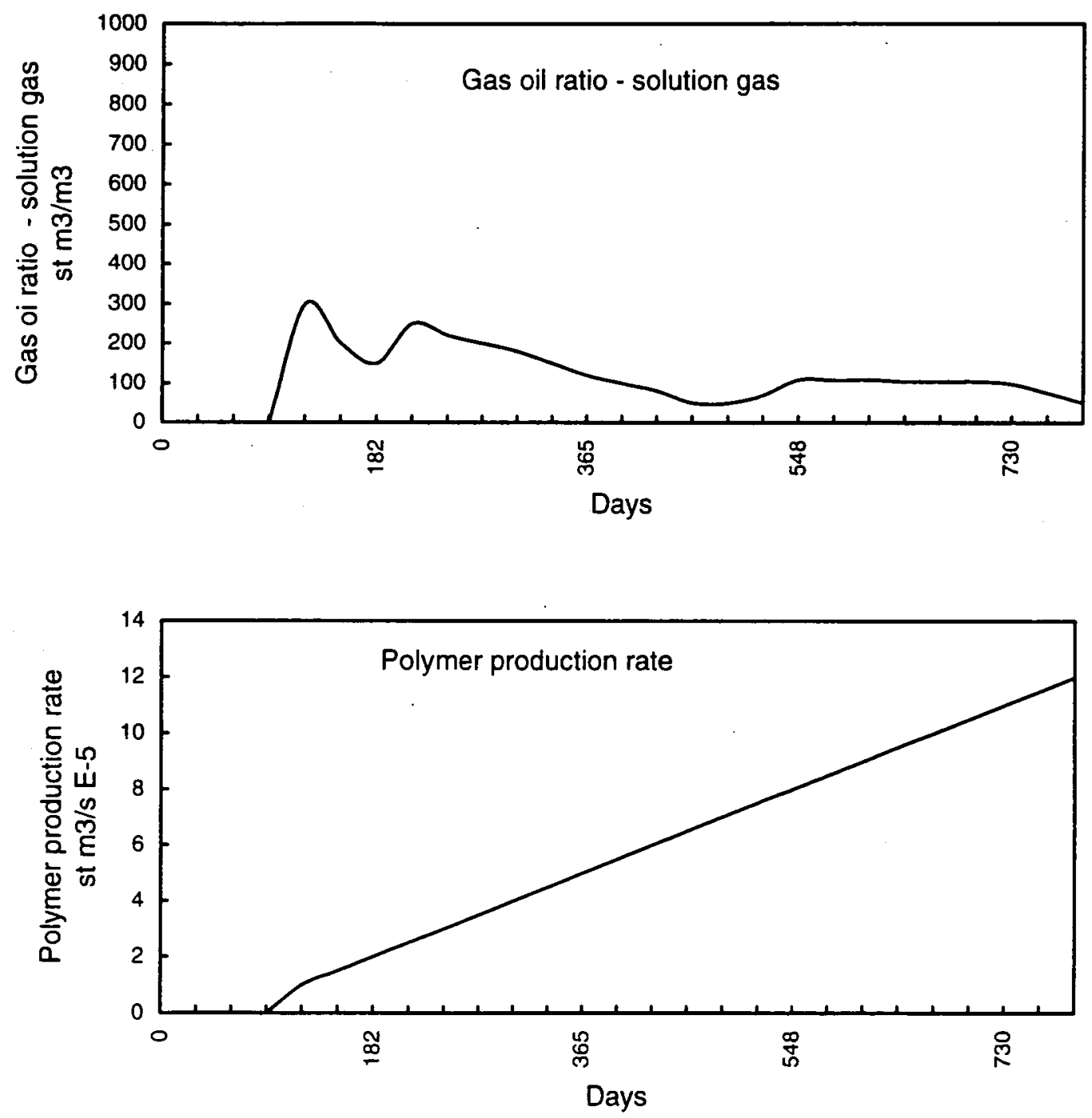
Fig. 4 - Water cut vs time - Polymer injection rate $=0,00092 \mathrm{m3} / \mathrm{s}$, polymer viscosity $=10 \mathrm{mPa} \mathrm{s}$

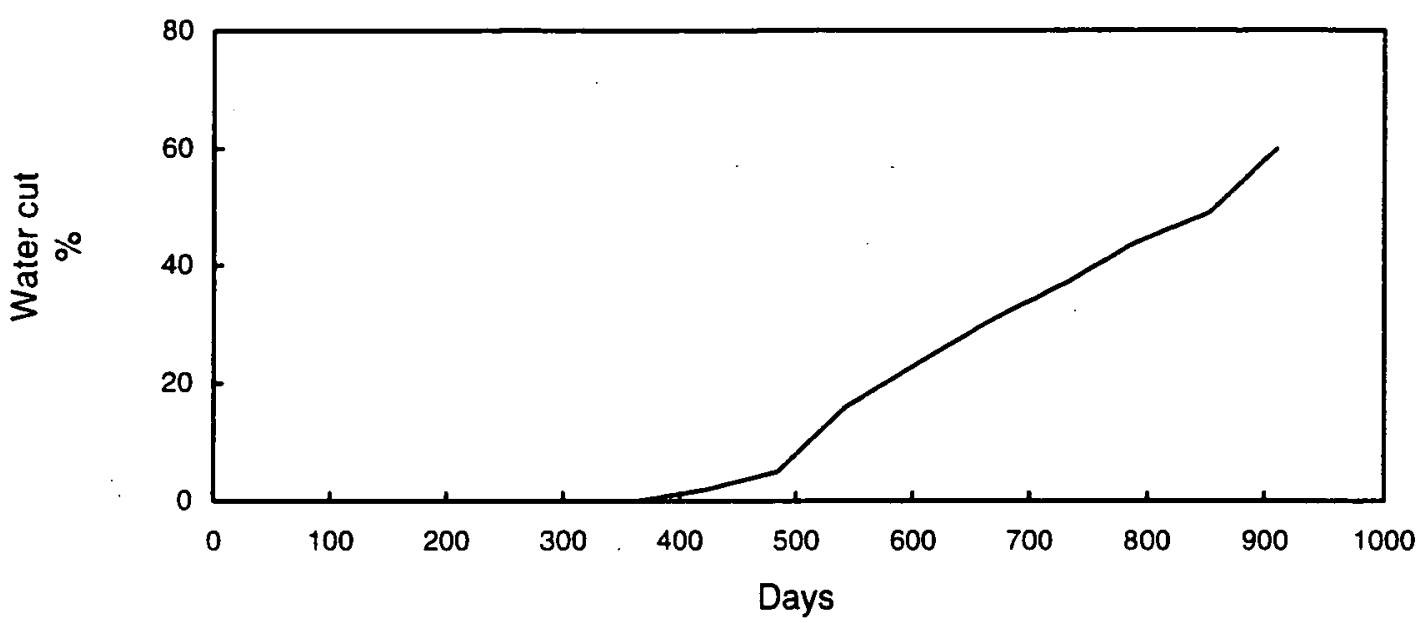

Fig.5 - Effect of polymer injection to contrast water coning on cumulative oil

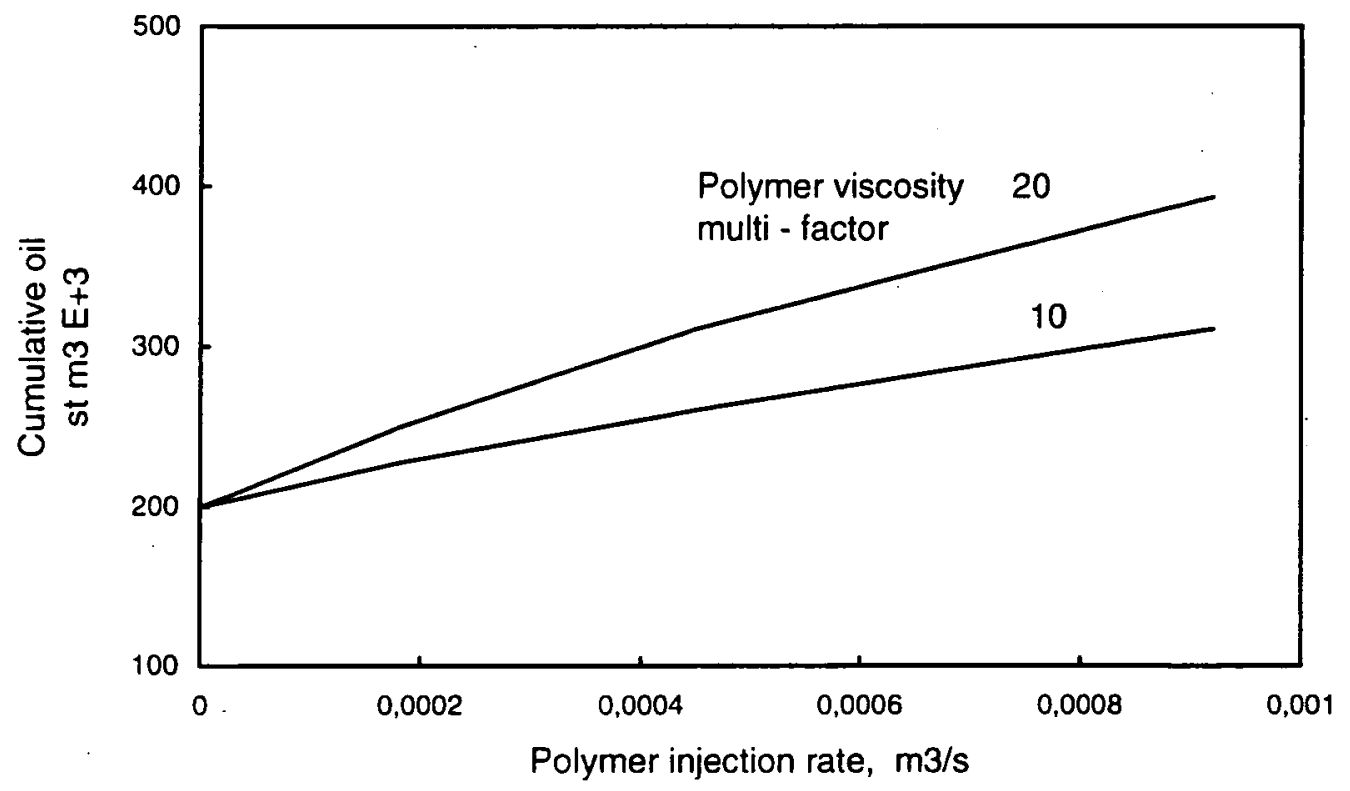


Fig. 6 - Optimum well completions for coning control by dynamic pressure barrier tecnique
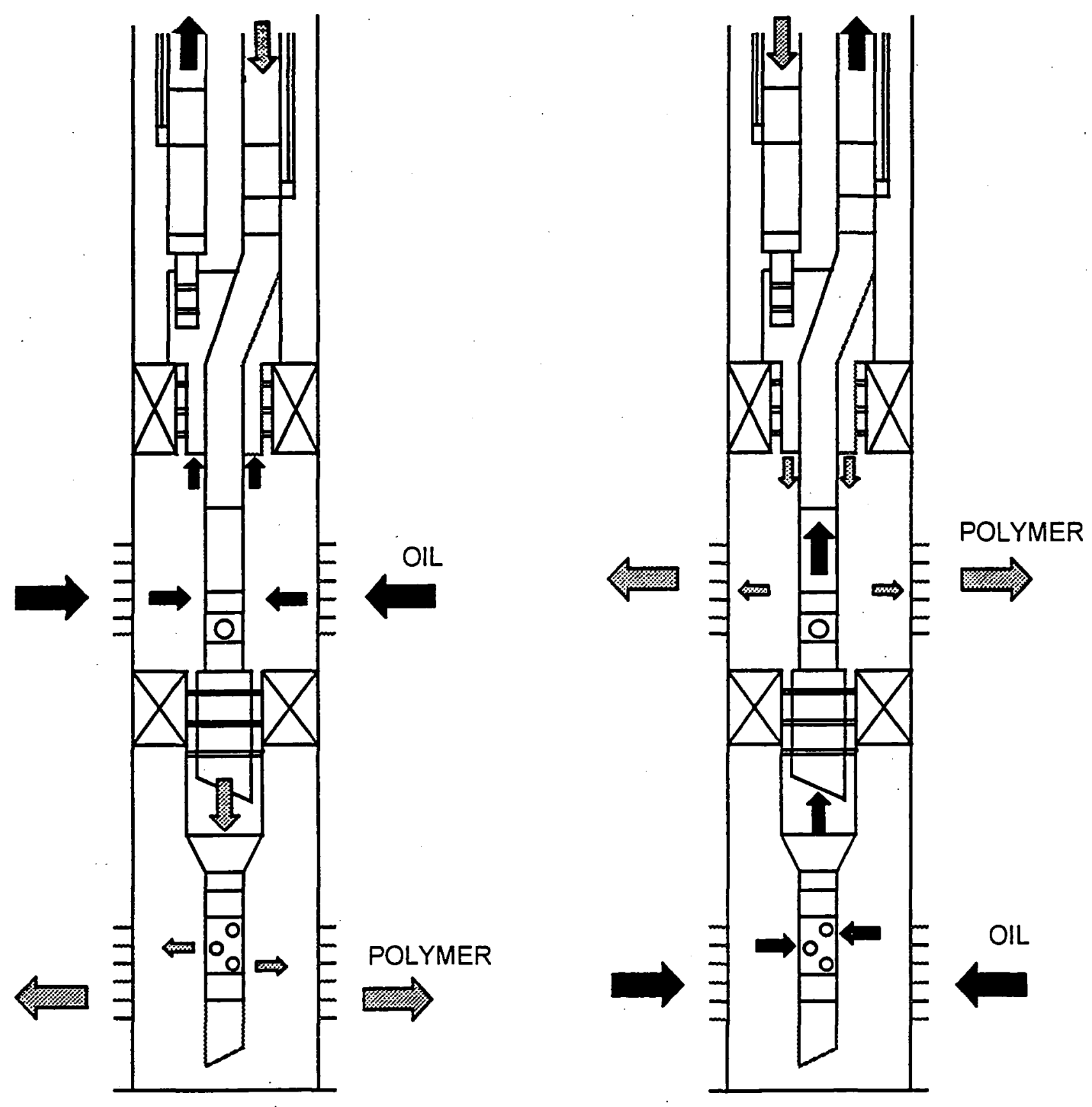